Published in final edited form as:

Br J Haematol. 2017 January ; 176(1): 86-91. doi:10.1111/bjh.14413.

\title{
Genomics of primary chemoresistance and remission induction failure in paediatric and adult acute myeloid leukaemia
}

Fiona C. Brown ${ }^{1}$, Paolo Cifani ${ }^{1}$, Esther Drill ${ }^{2}$, Jie He $^{3}$, Eric Still ${ }^{1}$, Shan Zhong ${ }^{3}$, Sohail Balasubramanian $^{3}$, Dean Pavlick ${ }^{3}$, Bahar Yilmazel ${ }^{3}$, Kristina M. Knapp ${ }^{4}$, Todd A. Alonzo ${ }^{5,6}$, Soheil Meshinchi ${ }^{5,7}$, Richard M. Stone ${ }^{8}$, Steven M. Kornblau ${ }^{9}$, Guido Marcucci ${ }^{10}$, Alan S. Gamis $^{5,11}$, John C. Byrd ${ }^{12}$, Mithat Gonen ${ }^{2}$, Ross L. Levine ${ }^{13}$, and Alex Kentsis ${ }^{1,14}$

${ }^{1}$ Molecular Pharmacology Program, Sloan Kettering Institute, Memorial Sloan Kettering Cancer Center, New York, NY, United States

${ }^{2}$ Department of Biostatistics and Epidemiology, Memorial Sloan Kettering Cancer Center, New York, NY, United States

${ }^{3}$ Foundation Medicine, Cambridge, MA, United States

${ }^{4}$ Leukemia Center, Memorial Sloan Kettering Cancer Center, New York, NY, United States

${ }^{5}$ Children's Oncology Group, Monrovia, CA, United States

${ }^{6}$ Department of Biostatistics, University of Southern California, Los Angeles, CA, United States

${ }^{7}$ Fred Hutchinson Cancer Research Center and the University of Washington School of Medicine, Seattle, WA, United States

${ }^{8}$ Division of Hematologic Malignancies, Dana-Farber Cancer Institute, Harvard Medical School, Boston, MA, USA

${ }^{9}$ Department of Leukemia, The University of Texas and MD Anderson Cancer Center, Houston, TX, United States

${ }^{10}$ Gehr Family Leukemia Center, City of Hope Comprehensive Cancer Center, Duarte, CA, United States

${ }^{11}$ Division of Hematology-Oncology/, Children's Mercy Hospitals and Clinics, Kansas City, MO, United States

${ }^{12}$ Division of Hematology, Department of Internal Medicine, The Ohio State University, Columbus, $\mathrm{OH}$, United States

${ }^{13}$ Human Oncology and Pathogenesis Program, Memorial Sloan Kettering Cancer Center and Weill Medical College of Cornell University, New York, NY, United States

Correspondence: Alex Kentsis, MD, PhD, Memorial Sloan Kettering Cancer Center, 1275 York Ave, New York, NY, USA 10065, Phone number: 1-646-888-2593; Fax: +1-646-422-0231; kentsisresearchgroup@gmail.com.

Authorship

FB and AK wrote the manuscript and performed analysis. FB, PC, ES performed laboratory experiments. JH, SZ, SB, DP and BY performed analysis. KK, TA, SM, RS, SK, GM, JB compiled patient samples. ED, MG and JH performed statistical analysis. AK and RL designed the study. RL contributed clinical and genomic expertise.

Conflict-of-interest disclosure: JH, SZ, SB, DP and BY are employees and equity holders of Foundation Medicine Inc. RL is a consultant for Foundation Medicine Inc. 
${ }^{14}$ Department of Pediatrics, Memorial Sloan Kettering Cancer Center and Weill Medical College of Cornell University, New York, NY, United States

\section{Abstract}

Cure rates of children and adults with acute myeloid leukaemia (AML) remain unsatisfactory partly due to chemotherapy resistance. We investigated the genetic basis of AML in 107 primary cases by sequencing 670 genes mutated in haematological malignancies. SETBP1, ASXL1 and $R E L N$ mutations were significantly associated with primary chemoresistance. We identified genomic alterations not previously described in AML, together with distinct genes that were significantly overexpressed in therapy-resistant AML. Defined gene mutations were sufficient to explain primary induction failure in only a minority of cases. Thus, additional genetic or molecular mechanisms must cause primary chemoresistance in paediatric and adult AML.

\section{Keywords}

Primary chemoresistance; Paediatric leukaemia; Cytogenetically normal acute myeloid leukaemia; Targeted deep sequencing genomics; Induction failure

For patients with acute myeloid leukaemia (AML), failure to achieve complete remission after induction therapy or relapse after complete remission represents the major barrier to cure for both children and adults. Despite recent efforts to improve risk stratification and to incorporate targeted therapies into AML therapy, relapse rates remain approximately $30 \%$ and 50\% for children and adults with AML, respectively (de Rooij et al., 2015, Breems et al., 2005). Whilst leukaemia cytogenetics at the time of diagnosis has proven to be the most useful prognostic biomarker of clinical outcomes and therapy stratification, patients with cytogenetically normal (CN) AML encompass the largest group for whom prognostication and therapy selection are hindered by the lack of prognostic markers and effective therapeutic targets.

Genomic profiling has been used to stratify patients with CN AML, identifying recurrent somatic gene mutations, such as those in NPM1, TET2, ASXL1, and DNMT3A, that are significantly associated with clinical outcomes (Kihara et al., 2014). Recent studies using whole-genome sequencing have assessed the mutational landscape of relapsed AML in adults, identifying two major patterns of clonal evolution in response to chemotherapy: 1) persistence of the dominant pre-leukaemic clone with mutations acquired at relapse and 2) expansion of a diagnostic sub-clones, emphasizing the importance of therapeutically targeting specific molecular mechanisms that contribute to chemotherapy resistance (Ding et al., 2012). Similar observations were recently made using genomic studies of paediatric AML, with responses of specific genetic clones representing potential prognostic indicators (Farrar et al., 2016). Clonal persistence after induction chemotherapy appears to be associated with the increased risk of relapse (Klco et al., 2015), but whether these mutant clones directly cause chemoresistance or reflect age-related clonal haematopoiesis remains to be determined (Wong et al., 2016). Importantly, the molecular basis of primary chemotherapy resistance, and thus fundamental causes of chemoresistance in general, remain poorly understood. Here, we used targeted gene sequencing of the majority of genes 
known to be recurrently mutated in haematological malignancies to identify diagnostic gene mutations that are associated with primary chemoresistance in adult and paediatric $\mathrm{CN}$ AML.

Specimens were collected from patients treated at the Memorial Sloan Kettering Cancer Center, MD Anderson Cancer Center, Dana-Farber Cancer Institute, Ohio State University Comprehensive Cancer Center and Children's Oncology Group (COG) participating institutions. All patients provided informed consent and were enrolled on respective institutional research protocols. Primary chemoresistance was defined based on the presence of at least 5\% of abnormal blasts by morphological and immunophenotypic assessment of bone marrow aspirates obtained after two cycles of induction chemotherapy, as assessed by respective institutional or central pathological reviews. Detailed description of methods of specimen preparation is provided in the Supplementary Methods.

Targeted DNA and RNA capture and sequencing of 670 genes (405 genes in DNA and 265 genes in RNA) known to be recurrently mutated in haematological malignancies were performed using the Foundation One (Cambridge, MA) Heme sequencing platform. High quality reads were obtained from Illumina sequencing at an average read depth of $503 \mathrm{x}$ (range 263-746 x) and variants were annotated and filtered as previously reported (He et al., 2016). Variant allele frequency (VAF) was used to estimate mutation clonality (Supplementary methods). Differential gene expression analysis was performed based on per million processing regions (PPM) gene expression measurements, as median normalized to all other AML specimens analysed to date (He et al., 2016). Detailed statistical analyses are described in Supplementary methods.

In total, genomic profiles of $107 \mathrm{CN}$ AML specimens were obtained from 55 adults and 52 children (Table I). No significant differences were observed in the total number of coding mutations between the primary failure of induction chemotherapy and complete remission outcome groups for both paediatric and adult cohorts (Table SI). Although the adult cohort represents a heterogeneous population based on varying treatment regimens, genetic status (both number of mutations per patient and specific alterations) was not significantly different between induction therapy programs (Table SI). Consistent with previous studies, the most frequently mutated genes among adults were DNMT3A (49\%), FLT3 (42\%) and NPM1 (42\%), and for paediatric patients FLT3 (54\%), NRAS (27\%) and WT1 (25\%), which were not significantly associated with either outcome group (Figure 1). DNMT3A and NPM1 mutations were relatively rare in paediatric $(2 \%)$ as compared to adult cases $(p<0.001$, permutation test). In contrast, heterozygous $C E B P A$ mutations were more frequently observed in paediatric as compared to adult CN AML (21\% versus $2 \%$, respectively, $p<$ 0.001 , permutation test). Genomic profiling also identified 15 gene rearrangements among the 21 specimens for which diagnostic material of adequate quality was available for RNA capture (Table SI). Cryptic rearrangements of known genes in AML were detected, including KMT2A (MLL) and NUP98-NSD1. The latter was observed uniquely in paediatric patients from this study, consistent with previous reports (Hollink et al., 2011). We identified several cryptic gene rearrangements, including intergenic deletions involving NOTCH1/EDF1 and GATA2/DNAJB8, which have not ben previously described, as well as translocations leading to the rearrangements of SQSTM1-NUP214 and IGH-BCL2. 
Mutations of these genes have been reported in haematological malignancies, e.g. SQSTM1NUP214 gene fusion in cases of T-cell acute lymphoblastic leukaemias (ALL), but not in AML (Gorello et al., 2010). In addition, our study identified potential novel coding mutations in MAP3K1 (MEKK), MAP3K6 (MEKKG), EP300 (p300), and WDR90 (Table SI). These findings emphasize the value of genomic profiling to identify potential pathogenic lesions that may elude conventional cytogenetic analyses and diagnosis based on morphological or immunophenotypic studies.

We assessed whether any gene mutations were significantly associated with primary chemoresistance as compared to complete remission among the adult and paediatric patients in the studied cohorts. This identified mutations of SETBP1 (8 out of 50 versus 1 out of 57, $p=0.01$ ) and $A S X L 1$ ( 7 out of 50 versus 1 out of 57, $p=0.02$ ), as well as RELN (8 out of 50 versus 2 out of 57, $p=0.04$, permutation test). With the exception of $A S X L 1$, which exhibited equal numbers of clonal and subclonal mutations, all SETBP1 and 70\% of RELN mutations were clonal (Table SII). None of the other apparently subclonal mutations, including those of FLT3, NPM1, KIT and NRAS, were found to be significantly associated with primary chemoresistance, when adjusted for multiple hypothesis testing (Table SII). Mutations of SETBP1 and $A S X L 1$ have been associated with inferior outcomes and increased risk of relapse in patients with AML (Meggendorfer et al., 2013). Relapseassociated SETBP1 mutations in AML commonly cause missense mutations in the SKI domain (p.858-871). Our analysis identified the missense p.D868N SETBP1 mutation in one CN AML specimen, as well as additional missense mutations of unknown significance (p.E183K, p.A374T, p.A408T, p.M502I, p.D1161H, p.T1547N and p.S1590C), suggesting that alternative mechanisms of SETBP1 dysregulation may exist in AML. Mutations of $R E L N$ have been reported in early T-cell precursor (ETP) ALL, a stem cell-like leukaemia with high rates of intrinsic chemotherapy resistance and genetic features that are shared with subtypes of AML (Zhang et al., 2012). Our findings of RELN mutations associated with primary chemoresistance in CN AML raise the possibility that these leukaemias may comprise a distinct biological entity.

Using the available RNA sequencing and gene expression data on 21 primary AML specimens from this cohort (He et al., 2016), we assessed whether the genes included in our analysis were significantly altered in expression in the induction failure as compared to complete remission cohorts (Table SIII). This analysis revealed significant overexpression of genes encoding DNA damage repair and response regulators [ATM, ATR, PSIP1 (LEDGF), and $E M S Y(C 11 O R F 30)$ ], an endoplasmic reticulum stress response regulator (HERPUD1), transcription factors $(C B F B, M E F 2 C)$, kinases [AKT3 and $M A P 3 K 7(T A K 1)$ ], metabolic enzymes ( $L D H A, A C S L G$ ), clathrin (CLTC) and an immune regulator (CTLA4; $p<0.05$, ttest). Indeed, recent studies have implicated $M E F 2 C$ overexpression with inferior outcomes in paediatric AML (Laszlo et al., 2015). Additional profiling and functional studies will be necessary to establish their prevalence and pathogenicity in AML. These results suggest that other mechanisms, such as those involving epigenetic or functional molecular alterations of cell signalling, may also mediate chemotherapy response and failure.

In summary, we have assessed the mutational landscape of CN AML at diagnosis in adults and children to determine the genetic basis of induction failure and primary 
chemoresistance. In spite of careful selection of cytogenetically normal specimens, our study identified numerous cryptic gene rearrangements, including those that have potential therapeutic implications. Likewise, we found novel gene alterations including lesions that have been observed in non-myeloid haematological malignancies, some of which may be pathogenic. In addition, this analysis revealed significant overexpression of genes that are associated with primary chemotherapy resistance. Though mutations of SETBP1, ASXL1 and RELN appear to be associated with primary chemoresistance and induction failure in our study, their prevalence was relatively low. We did not identify single gene mutations that appeared to be significantly associated with primary chemoresistance and induction failure in the majority of the patients studied. It is possible that additional genetic lesions, such as those not included in the current target gene panel (He et al., 2016), or alternatively, combinations of genetic alterations that are below the statistical power of our study may cause chemotherapy resistance and failure in AML, which may be elucidated by larger and more comprehensive genomic profiling studies. Finally, it remains to be determined whether functional molecular profiling, such as that achieved using gene expression, epigenetic and proteomic analyses, may reveal generally useful biomarkers and therapeutic targets to prospectively identify and therapeutically block chemotherapy resistance in AML ( Chan et al., 2015, Rijal et al., 2015).

\section{Supplementary Material}

Refer to Web version on PubMed Central for supplementary material.

\section{Acknowledgments}

We thank Alejandro Gutierrez for critical discussions. This work was supported by the NIH R21 CA188881, K08 CA160660, P30 CA008748, U10 CA180899, Burroughs Wellcome Fund, Alex's Lemonade Stand Foundation, Gabrielle's Angel Foundation, and the Josie Robertson Investigator Program. AK is the Damon Runyon-Richard Lumsden Foundation Clinical Investigator.

\section{References}

Breems DA, Van Putten WL, Huijgens PC, Ossenkoppele GJ, Verhoef GE, Verdonck LF, Vellenga E, De Greef GE, Jacky E, Van Der Lelie J, Boogaerts MA, Lowenberg B. Prognostic index for adult patients with acute myeloid leukemia in first relapse. J Clin Oncol. 2005; 23:1969-78. [PubMed: 15632409]

Chan SM, Thomas D, Corces-Zimmerman MR, Xavy S, Rastogi S, Hong WJ, Zhao F, Medeiros BC, Tyvoll DA, Majeti R. Isocitrate dehydrogenase 1 and 2 mutations induce BCL-2 dependence in acute myeloid leukemia. Nat Med. 2015; 21:178-84. [PubMed: 25599133]

De Rooij JD, Zwaan CM, Van Den Heuvel-Eibrink M. Pediatric AML: From Biology to Clinical Management. J Clin Med. 2015; 4:127-49. [PubMed: 26237023]

Ding L, Ley TJ, Larson DE, Miller CA, Koboldt DC, Welch JS, Ritchey JK, Young MA, Lamprecht T, Mclellan MD, Mcmichael JF, Wallis JW, Lu C, Shen D, Harris CC, Dooling DJ, Fulton RS, Fulton LL, Chen K, Schmidt H, Kalicki-Veizer J, Magrini VJ, Cook L, Mcgrath SD, Vickery TL, Wendl MC, Heath S, Watson MA, Link DC, Tomasson MH, Shannon WD, Payton JE, Kulkarni S, Westervelt P, Walter MJ, Graubert TA, Mardis ER, Wilson RK, Dipersio JF. Clonal evolution in relapsed acute myeloid leukaemia revealed by whole-genome sequencing. Nature. 2012; 481:50610. [PubMed: 22237025]

Farrar JE, Schuback HL, Ries RE, Wai D, Hampton OA, Trevino LR, Alonzo TA, Guidry Auvil JM, Davidsen TM, Gesuwan P, Hermida L, Muzny DM, Dewal N, Rustagi N, Lewis LR, Gamis AS, Wheeler DA, Smith MA, Gerhard DS, Meshinchi S. Genomic profiling of pediatric acute myeloid 
leukemia reveals a changing mutational landscape from disease diagnosis to relapse. Cancer Res. 2016; 26:2197-205.

Gorello P, La Starza R, Di Giacomo D, Messina M, Puzzolo MC, Crescenzi B, Santoro A, Chiaretti S, Mecucci C. SQSTM1-NUP214: a new gene fusion in adult T-cell acute lymphoblastic leukemia. Haematologica. 2010; 95:2161-3. [PubMed: 20851865]

He J, Abdel-Wahab O, Nahas MK, Wang K, Rampal RK, Intlekofer AM, Patel J, Krivstov A, Frampton GM, Young LE, Zhong S, Bailey M, White JR, Roels S, Deffenbaugh J, Fichtenholtz A, Brennan T, Rosenzweig M, Pelak K, Knapp KM, Brennan KW, Donahue AL, Young G, Garcia L, Beckstrom ST, Zhao M, White E, Banning V, Buell J, Iwanik K, Ross JS, Morosini D, Younes A, Hanash AM, Paietta E, Roberts K, Mullighan C, Dogan A, Armstrong SA, Mughal T, Vergilio JA, Labrecque E, Erlich R, Vietz C, Yelensky R, Stephens PJ, Miller VA, Van Den Brink MR, Otto GA, Lipson D, Levine RL. Integrated genomic DNA/RNA profiling of hematologic malignancies in the clinical setting. Blood. 2016; 127:3004-14. [PubMed: 26966091]

Hollink IH, Van Den Heuvel-Eibrink MM, Arentsen-Peters ST, Pratcorona M, Abbas S, Kuipers JE, Van Galen JF, Beverloo HB, Sonneveld E, Kaspers GJ, Trka J, Baruchel A, Zimmermann M, Creutzig U, Reinhardt D, Pieters R, Valk PJ, Zwaan CM. NUP98/NSD1 characterizes a novel poor prognostic group in acute myeloid leukemia with a distinct HOX gene expression pattern. Blood. 2011; 118:3645-56. [PubMed: 21813447]

Kihara R, Nagata Y, Kiyoi H, Kato T, Yamamoto E, Suzuki K, Chen F, Asou N, Ohtake S, Miyawaki S, Miyazaki Y, Sakura T, Ozawa Y, Usui N, Kanamori H, Kiguchi T, Imai K, Uike N, Kimura F, Kitamura K, Nakaseko C, Onizuka M, Takeshita A, Ishida F, Suzushima H, Kato Y, Miwa H, Shiraishi Y, Chiba K, Tanaka H, Miyano S, Ogawa S, Naoe T. Comprehensive analysis of genetic alterations and their prognostic impacts in adult acute myeloid leukemia patients. Leukemia. 2014; 28:1586-95. [PubMed: 24487413]

Klco JM, Miller CA, Griffith M, Petti A, Spencer DH, Ketkar-Kulkarni S, Wartman LD, Christopher M, Lamprecht TL, Helton NM, Duncavage EJ, Payton JE, Baty J, Heath SE, Griffith OL, Shen D, Hundal J, Chang GS, Fulton R, O'laughlin M, Fronick C, Magrini V, Demeter RT, Larson DE, Kulkarni S, Ozenberger BA, Welch JS, Walter MJ, Graubert TA, Westervelt P, Radich JP, Link DC, Mardis ER, Dipersio JF, Wilson RK, Ley TJ. Association Between Mutation Clearance After Induction Therapy and Outcomes in Acute Myeloid Leukemia. JAMA. 2015; 314:811-22. [PubMed: 26305651]

Laszlo GS, Alonzo TA, Gudgeon CJ, Harrington KH, Kentsis A, Gerbing RB, Wang YC, Ries RE, Raimondi SC, Hirsch BA, Gamis AS, Meshinchi S, Walter RB. High expression of myocyte enhancer factor 2C (MEF2C) is associated with adverse-risk features and poor outcome in pediatric acute myeloid leukemia: a report from the Children's Oncology Group. J Hematol Oncol. 2015; 8:115. [PubMed: 26487643]

Meggendorfer M, Bacher U, Alpermann T, Haferlach C, Kern W, Gambacorti-Passerini C, Haferlach T, Schnittger S. SETBP1 mutations occur in $9 \%$ of MDS/MPN and in $4 \%$ of MPN cases and are strongly associated with atypical CML, monosomy 7, isochromosome i(17)(q10), ASXL1 and CBL mutations. Leukemia. 2013; 27:1852-60. [PubMed: 23628959]

Rijal S, Fleming S, Cummings N, Rynkiewicz NK, Ooms LM, Nguyen NY, Teh TC, Avery S, Mcmanus JF, Papenfuss AT, Mclean C, Guthridge MA, Mitchell CA, Wei AH. Inositol polyphosphate 4-phosphatase II (INPP4B) is associated with chemoresistance and poor outcome in AML. Blood. 2015; 125:2815-24. [PubMed: 25736313]

Wong TN, Miller CA, Klco JM, Petti A, Demeter R, Helton NM, Li T, Fulton RS, Heath SE, Mardis ER, Westervelt P, Dipersio JF, Walter MJ, Welch JS, Graubert TA, Wilson RK, Ley TJ, Link DC. Rapid expansion of preexisting nonleukemic hematopoietic clones frequently follows induction therapy for de novo AML. Blood. 2016; 127:893-7. [PubMed: 26631115]

Zhang J, Ding L, Holmfeldt L, Wu G, Heatley SL, Payne-Turner D, Easton J, Chen X, Wang J, Rusch M, Lu C, Chen SC, Wei L, Collins-Underwood JR, Ma J, Roberts KG, Pounds SB, Ulyanov A, Becksfort J, Gupta P, Huether R, Kriwacki RW, Parker M, Mcgoldrick DJ, Zhao D, Alford D, Espy S, Bobba KC, Song G, Pei D, Cheng C, Roberts S, Barbato MI, Campana D, Coustan-Smith E, Shurtleff SA, Raimondi SC, Kleppe M, Cools J, Shimano KA, Hermiston ML, Doulatov S, Eppert K, Laurenti E, Notta F, Dick JE, Basso G, Hunger SP, Loh ML, Devidas M, Wood B, Winter S, Dunsmore KP, Fulton RS, Fulton LL, Hong X, Harris CC, Dooling DJ, Ochoa K, Johnson KJ, Obenauer JC, Evans WE, Pui CH, Naeve CW, Ley TJ, Mardis ER, Wilson RK, Downing JR, 
Mullighan CG. The genetic basis of early T-cell precursor acute lymphoblastic leukaemia. Nature. 2012; 481:157-63. [PubMed: 22237106] 


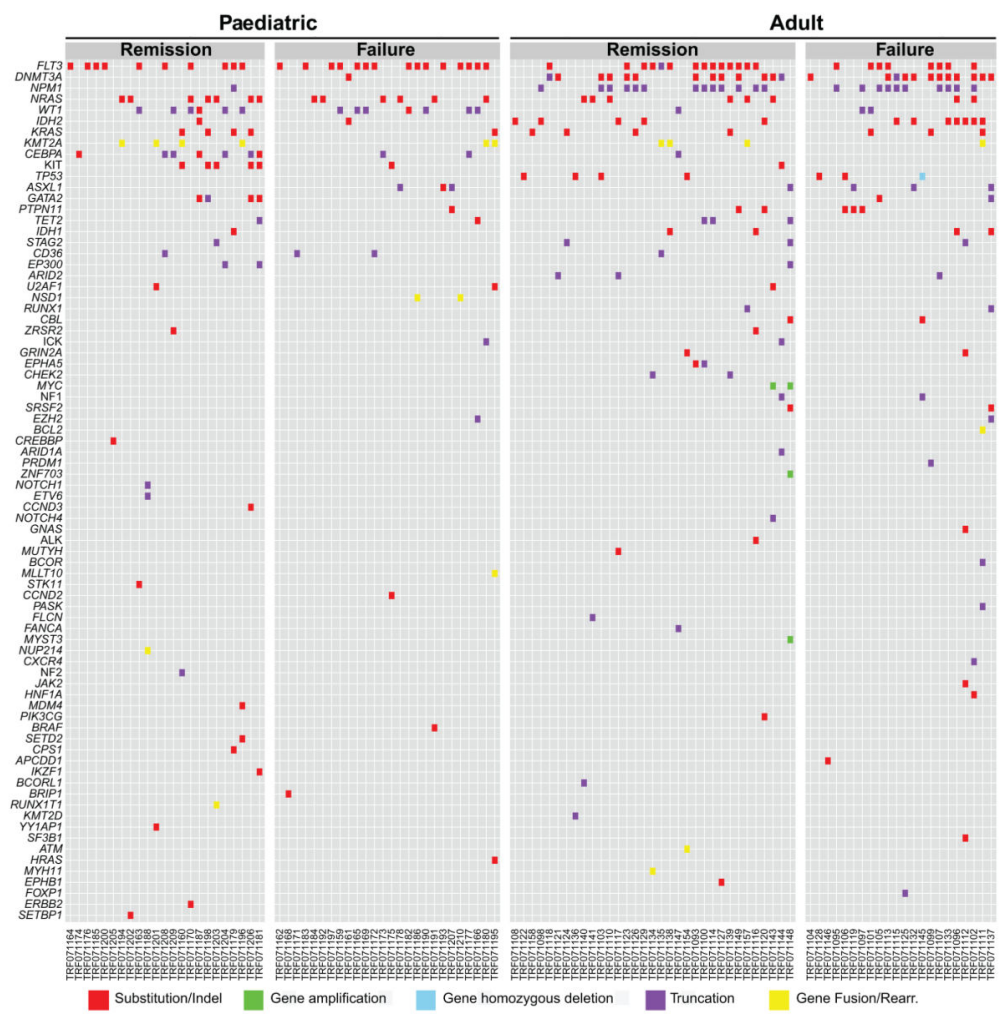

Figure 1. Mutational spectrum of paediatric and adult acute myeloid leukaemia with primary chemotherapy resistance and induction failure

Tile plot of the genomic alterations identified in DNA/RNA targeted sequencing. Data are shown for 107 cytogenetically normal acute myeloid leukaemia specimens, collected from 52 and 57 adult and paediatric specimens respectively, grouped by clinical outcome. Only genomic alterations of known pathological significance are displayed (Table SI). 


\section{Table I}

Demographic features of induction failure and induction remission cohorts

\begin{tabular}{lcccc}
\hline & \multicolumn{2}{c}{ Paediatric } & \multicolumn{2}{c}{ Adult } \\
Characteristics & Remission & Failure & Remission & Failure \\
\hline Number, N (\%) & $25(48)$ & $27(52)$ & $32(58)$ & $23(42)$ \\
\hline Gender, \% female & 52 & 44 & 47 & 39 \\
\hline Age (years), median (range) & $11.5(2.8-16.8)$ & $10.4(0.6-16.8)$ & $48.4(19-84)$ & $54.7(16-73)$ \\
\hline Therapy, N (\%) & & & & \\
\hline ADE & $25(48)$ & $27(52)$ & 0 & 0 \\
\hline IDA + HDAC & 0 & 0 & $10(31.2)$ & $4(17.4)$ \\
\hline $7+3$ DNR and AraC & 0 & 0 & $11(34.4)$ & $14(60.9)$ \\
\hline FAI & 0 & 0 & $4(12.5)$ & $1(4.3)$ \\
\hline BID-FA & 0 & 0 & $2(6.25)$ & $2(8.7)$ \\
\hline FLAG-IDA & 0 & 0 & $4(12.5)$ & $0(0)$ \\
\hline IDA + AraC & 0 & 0 & $1(3.1)$ & $1(4.3)$ \\
\hline Clofa + IDA + AraC & 0 & 0 & 0 & $1(4.3)$ \\
\hline
\end{tabular}

Abbreviations: ADE, cytarabine, daunomycin and etoposide-based regimen; IDA, idarubicin; HDAC, high-dose cytarabine; DNR, daunorubicin; BID-FA, twice daily fludarabine + cytarabine; FAI, fludarabine, cytarabine, idarubicin; FLAG-IDA, fludarabine, cytarabine, idarubicin and granulocyte colony stimulating factor; Clofa, clofarabine; AraC, cytarabine. 